\title{
Analysis of Highway Slope Failure by Using Stereographic Projection Method
}

\author{
Bharat Prasad Bhandari ${ }^{1}$ and Tark Raj Joshi ${ }^{2}$ \\ ${ }^{1}$ Department of Civil Engineering, Thapathali Engineering College, Tribhuvan University, Kathmandu \\ ${ }^{2}$ Department of Science and Technology, Far Western University, Central campus, Kanchanpur, Nepal \\ Correspondence author: tarkraj2001@gmail.com
}

\begin{abstract}
This study was conducted at the Bhasu Bhir of Kailali district in the Far-western Province, along the Khanidanda-Sahajpur road section of Bhimdatta pant highway. The main objective of this study is to identify the potential slope failure area and assess the major control factors along the road section. To accomplish the objective, the dip amount and dip direction of major discontinuity was measured in the field along with hill slope and hill slope direction. The data of 40 locations were analyzed by using stereographic projection method. The result was obtained by using Dips 6.0 software. The major slope failures obtained on the area were wedge failure and plane failure. The hill slope geometry, joint status and rock geometry are found major controlling factors for the slope failure in the study area.
\end{abstract}

Key words: Hill slope, Joint status, Siwalik, Slope failure, Stereographic projection.

\section{Introduction}

In Nepal, most of the highway road lies either along the river bank or along the steep slope hill. The highways passing through the rocky terrain with steep slopes are vulnerable to rock fall and slope failure. The down slope movement of material is basically caused due to driving factor like gravity and triggering factors like engineering construction, which is termed as slope failures. It is also called as rock mass wasting (Hughes, 2003). The natural factors responsible for slope failure are steepness of slope, inclusion of the ground water, rainfall erosion, etc, whereas over the years, anthropogenic activities, such as infrastructure development and wrong human settlement practices also significantly contribute to an increase in slope failure. The exposed rock mass in Himalaya, which is already deformed, with steeper cut slopes along roads may prone to failure (Umrao et.al., 2011).Unfortunately, slope failure is a geo-hazard that impacts a wide range of landscapes and also many types of infrastructures. Among them landslide is the most catastrophic geohazard that cause the hundreds of death and injuries and hundreds of billions damage each year. Landslide involves the variety of combined process like falls, topple, avalanche and flow. Among them toppling is the most common deformation and failure for rock slope (Regmi et.al., 2014).

\subsection{Types of failure}

Generally, the rock mass failures modes are of three types: plane failure, wedge failure and toppling failure. A plane failure is likely to occur when a discontinuity dips in the same direction (within 20 degree) as the slope face, at an angle gentler than the slope angle but greater than the friction angle along the failure plane (Hoek \& Bray, 2014). Wedge failure is caused by 
discontinuities striking obliquely to the slope face where sliding of a wedge of rock takes place along the line of intersection of two such planes (Wyllie \& Mah, 2014). A wedge failure may occur when the line of intersection of two discontinuities, forming the wedge-shaped block, plunges in the same direction as the slope face and the plunge angle is less than the slope angle but greater than the friction angle along the planes of failure (Hoek \& Bray, 2014). The formation and occurrence of wedge failures are dependent primarily on lithology and structure of the rock mass (Piteau, 1972). Topple involves rotation of columns or blocks of rock about a fixed base (Wyllie \& Mah, 2014). A toppling failure may result when a steeply dipping discontinuity is parallel to the slope face (within 30 degree) and dips into it (Hoek \& Bray, 2014). Toppling failure involves inter-layer slip movement (Goodman, 1989).

\subsection{Stereographic projection}

Stereographic projection is a methodology used in structural geology and engineering to analyze orientation of lines and planes with respect to each other (Sanuja, 2016). Stereographic projection is used to represent a sphere of 2D plane in 3D model. In this projection point is set up with $\mathrm{x}$ - axis and $\mathrm{y}$ - axis. The relation between the points and the plane and the points on the sphere is called stereographic projection. The main aim of stereographic projection is for making maps. Different types of projection is done for the mapping such as equatorial projection, polar projection etc. (Sanuja, 2016). A standardized mapping system known as stereonets, are used to project different lines and planes in stereographic projections (Admassu, 2012). On stereographic projection, a sliding envelope of a multi-faced slope is a union of envelopes of individual faces formed on the slope surface. Sliding modes of multi-faced slopes are divided into two types and they are further subdivided into two modes, respectively; Type 1 single or double plane sliding and Type 2 single or double plane sliding (Yoon et al., 2002).

This paper aims to analyze the slope failure probability of Bhasu hill, along the Khanidanda Sahajpur road section of Bhimdatta pant highway of Far Western province Nepal. Bhimdatta Pant highway joins the hilly districts of far western with low land terai .The proposed section of highway seems susceptible to the geohazard, so to find out potential failure area is essential for this region. Tamrakar et.al., (2013) studied the slope stability along the river bank of Malekhu Khola and found that wedge and topple failure are very common along the Malekhu River section. Chamlagain and Dangol (2001) studied the slope failure mechanism of Mai Khola rockslide and thus concluded that the combination of plane and wedge failure along the dip slope in moderately weathered schistose gneiss, and highly fractured quartzite is the main cause of landslide. Muglin-Narayanghat is one of the most landslide affected road section of Nepal. Topple failure is the most prominent type of failure along with rock slide, debris slide/flow and some combination of these (Regmi et.al., 2014). 


\section{Materials and Methods}

\subsection{Study area:}

The study area has been selected at Bhasu Bhir of Kailali district, along Khanidanda- Sahajpur road section (Fig.1\& 2) of Bhimdatta Pant Highway (135km). The study area is characterized by steep rocky slope greater than $50^{\circ}$, composed of hard rock. The minimum and maximum elevation of study area is $1308 \mathrm{~m}$ to $1814 \mathrm{~m}$ respectively. The study area lies in Siwalik hill of Nepal. The Siwalik Hills is considered one of the most fragile and vulnerable in the Nepal Himalaya where soil erosion and landslide processes are very active partly due to its location within the zone of active crustal movement. However, comparatively there is very limited research on slope failure and kinematic analysis and processes in the Siwaliks of Far Western Nepal. The Siwalik Hills is the youngest Mountain of the world and geologically recent tropical mountain range characterized by steep and highly dissected terrain Known as the foothills of the Himalayas. The region is located between the Terai plain and the Lesser Himalayan zone. Geologically, the study area lies in Middle Siwalik. The area consists of very thick bedded, multistoried, pepper and salt sandstones, inter bedded with very thick grey mudstone. The thickness of sandstone bed varies from $30 \mathrm{~cm}$ to 10 $\mathrm{m}$. Most of the sandstones are dark grey in color.

Figure 1: Location map of study area

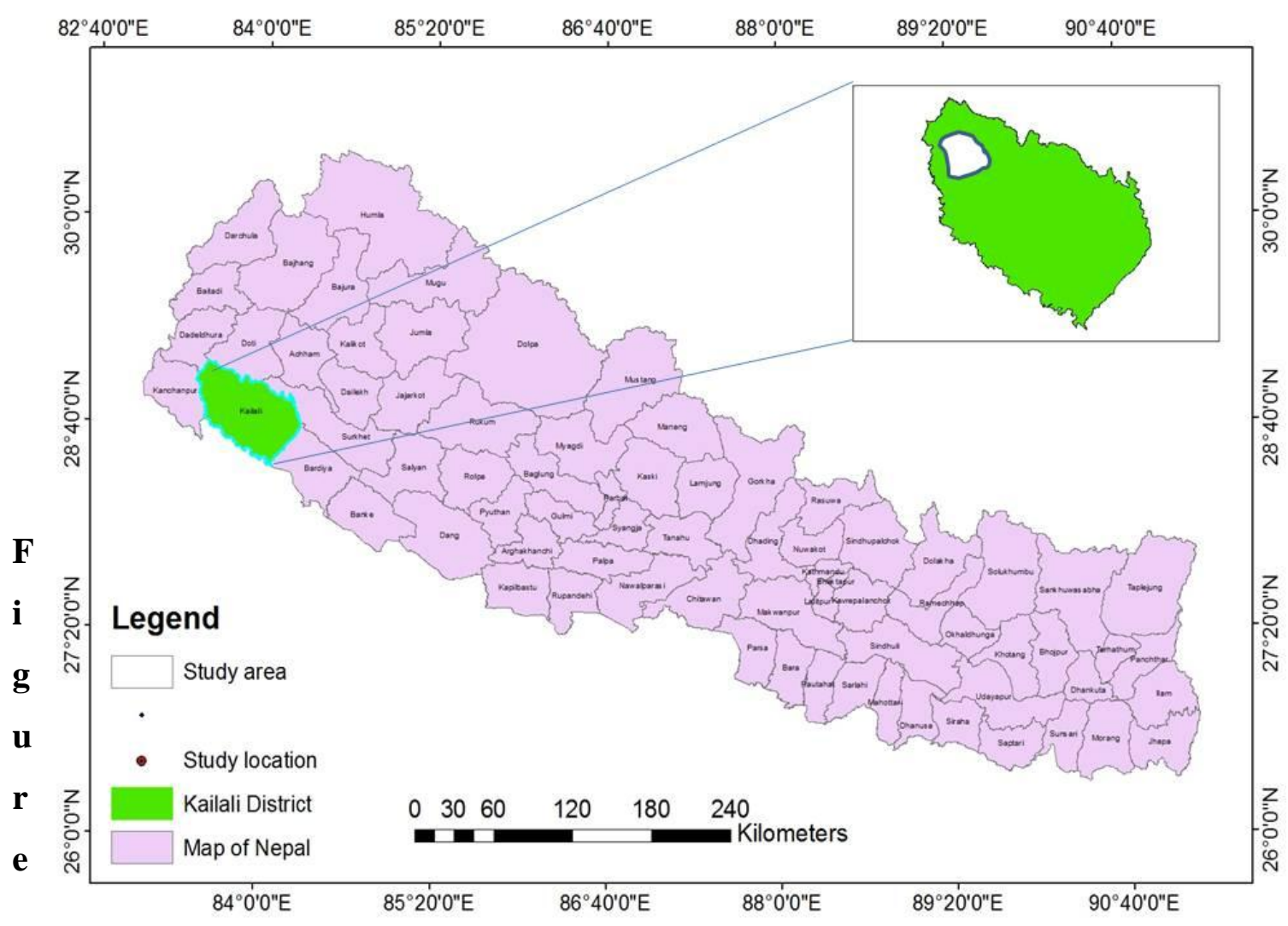




\section{2: Study area and locations of data collection}

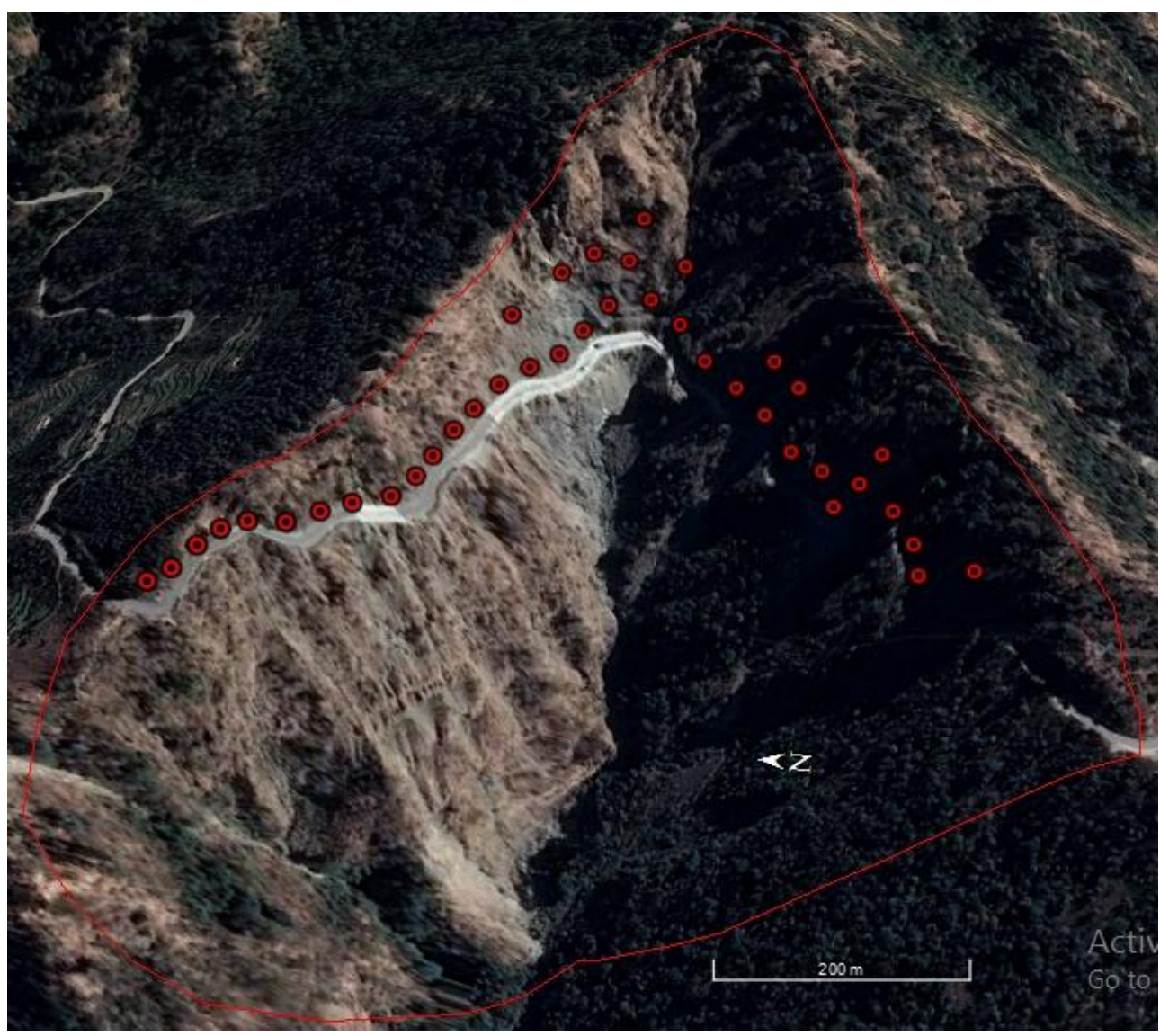

\subsection{Methods}

For the present study, $1000 \mathrm{~m}$ long, very steep slope of highway section was taken. The total distance is divided into 40 chainages where each chainage length was taken as $25 \mathrm{~m}$. The discontinuity sets of rock mass were measured by using Brunton compass. The dip amount and dip direction of joint sets were measured. The slope of hill and trend of hill was measured in each location. The rock mass rating was conducted in each location of discontinuity data measured. The data of 40 different locations were analyzed by using stereographic projection method. The failure type was analyzed in the Dips 6.0 software.

\section{Results and Discussion}

Three different types of failure are obtained namely plane failure, wedge failure and toppling failure. We observed 100\% plane failure and wedge failure in location 14 and 39 respectively. The percentage of each type of failure in each location is given in figure 3, 4, 5 and 6. Mostly, the probable wedge failure is found potential at the study area. Among the 40 locations, 23 locations have wedge failure possibility greater than $30 \%$ and in 17 locations, possibility of plane failure is greater than $30 \%$ (Fig.7). The major joints present in the bed rocks are, bedding joints, oblique joints and dip joints. The major cause of wedge failure in the study area is found dip and oblique joints present on bed rock. 
Figure 3: Different types of failure percentage in location 1 to 10.

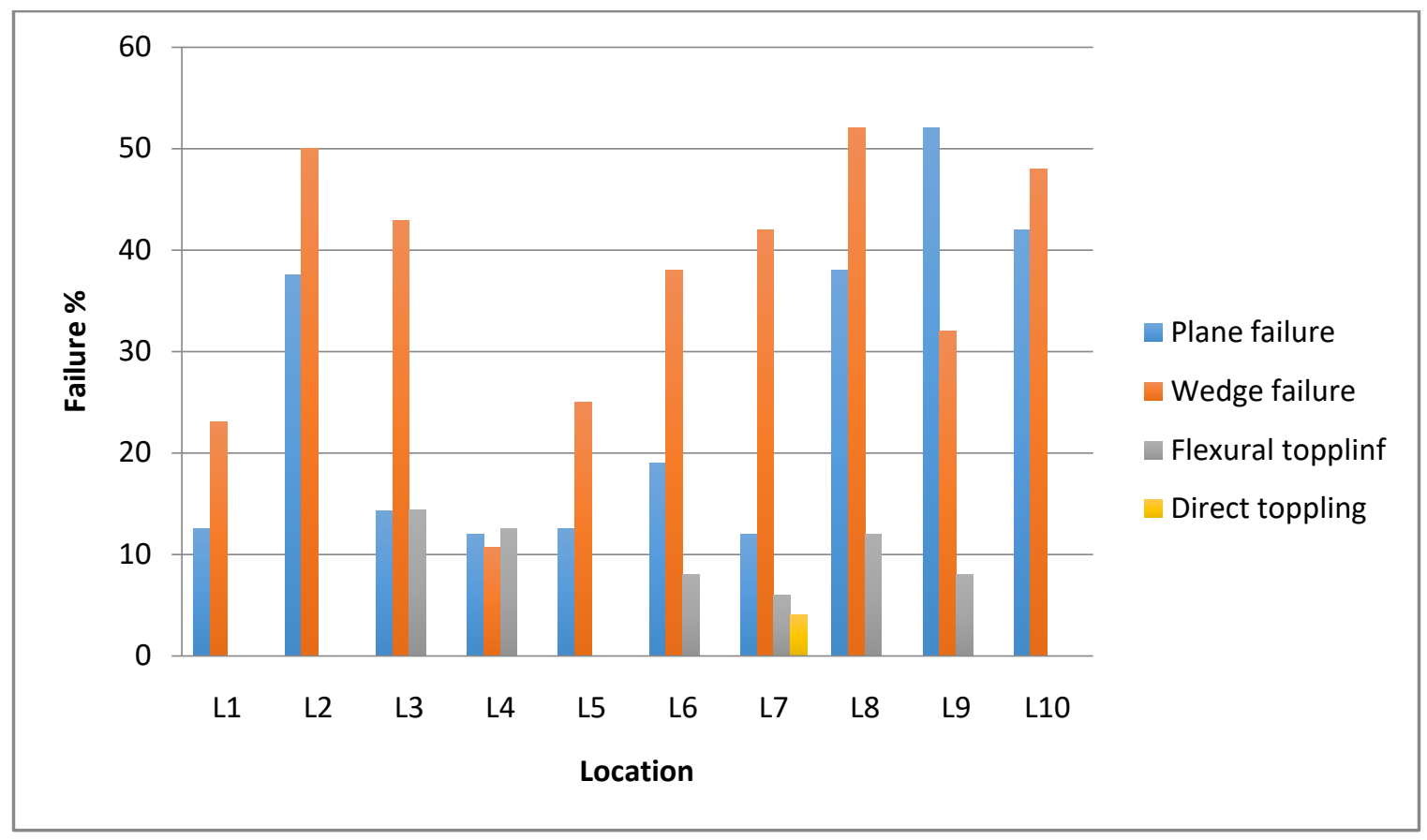

Figure 4: Different types of failure percentage in location 11 to 20.

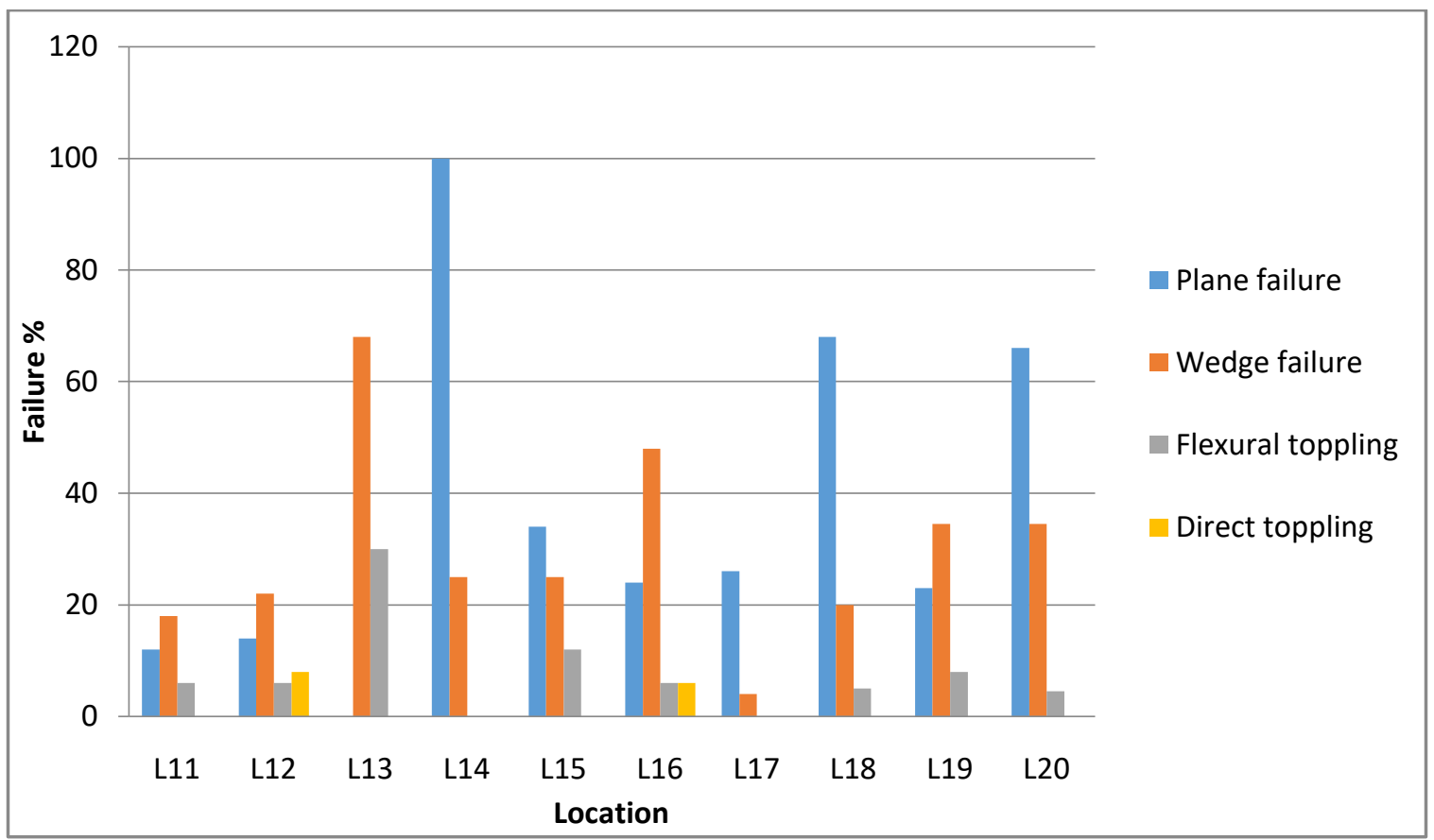


Figure 5: Different types of failure percentage in location 21 to 30.

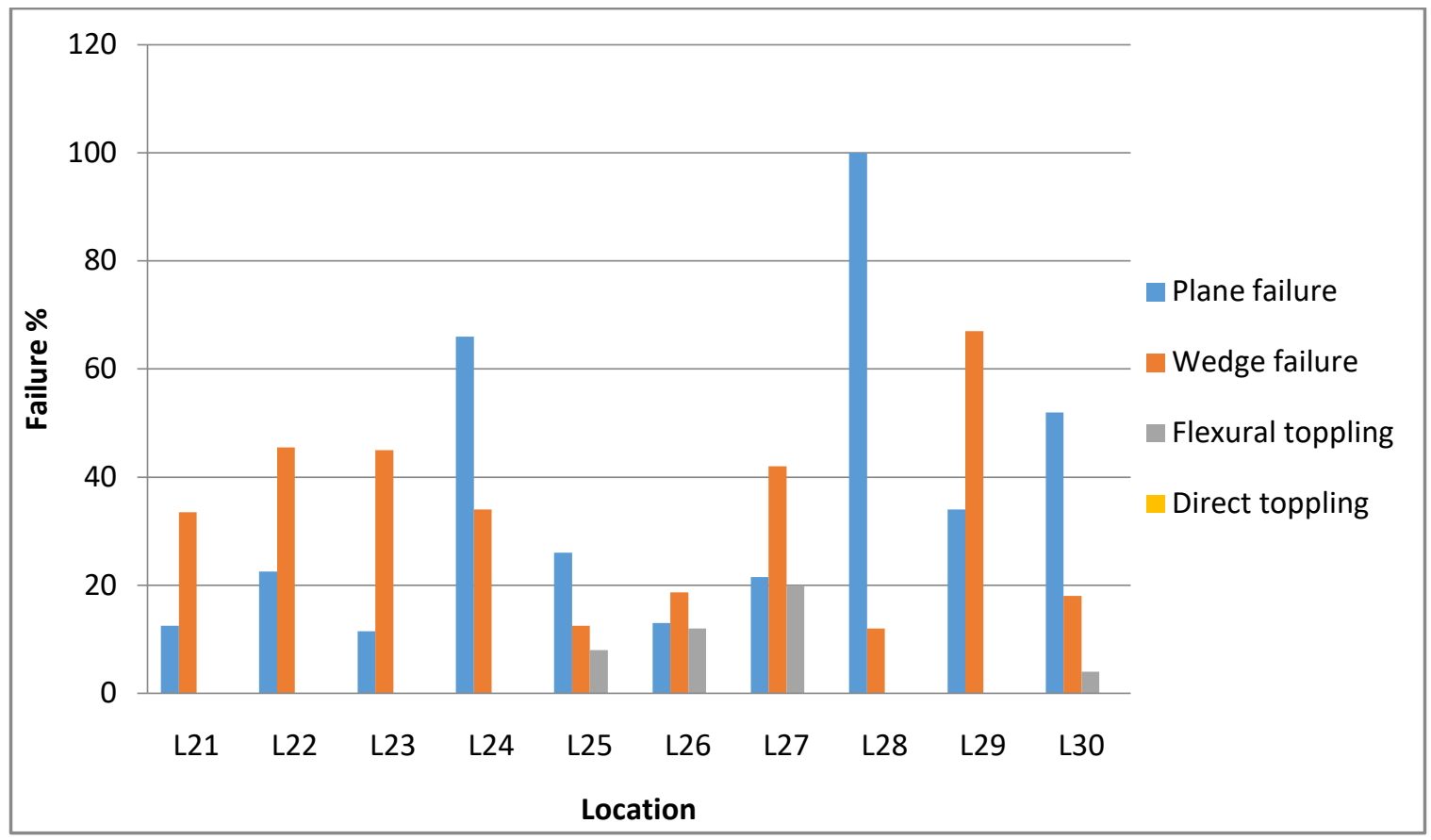

Figure 6: Different types of failure percentage in location 31 to 40.

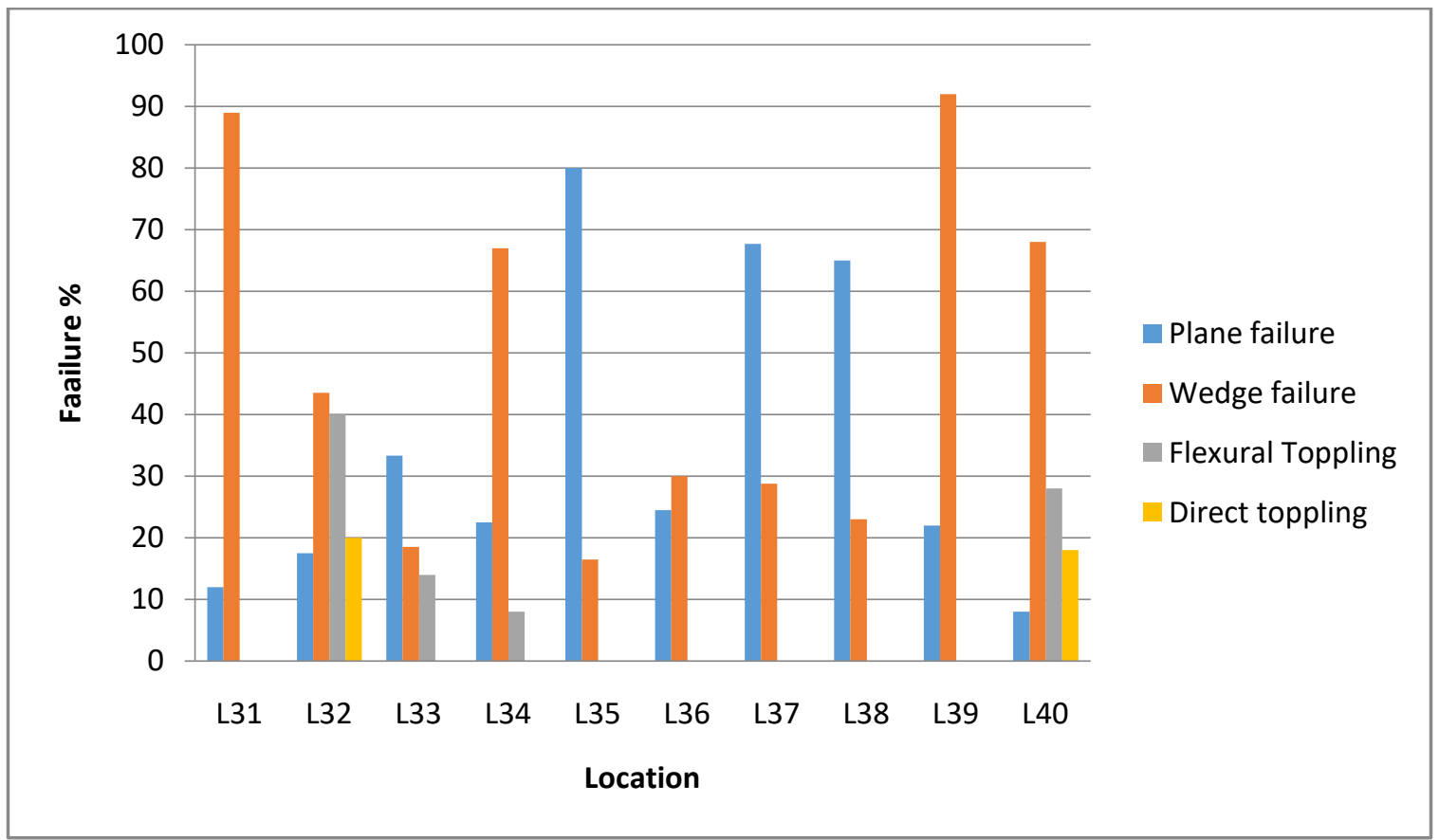


Figure 7: Failure percentage in different locations

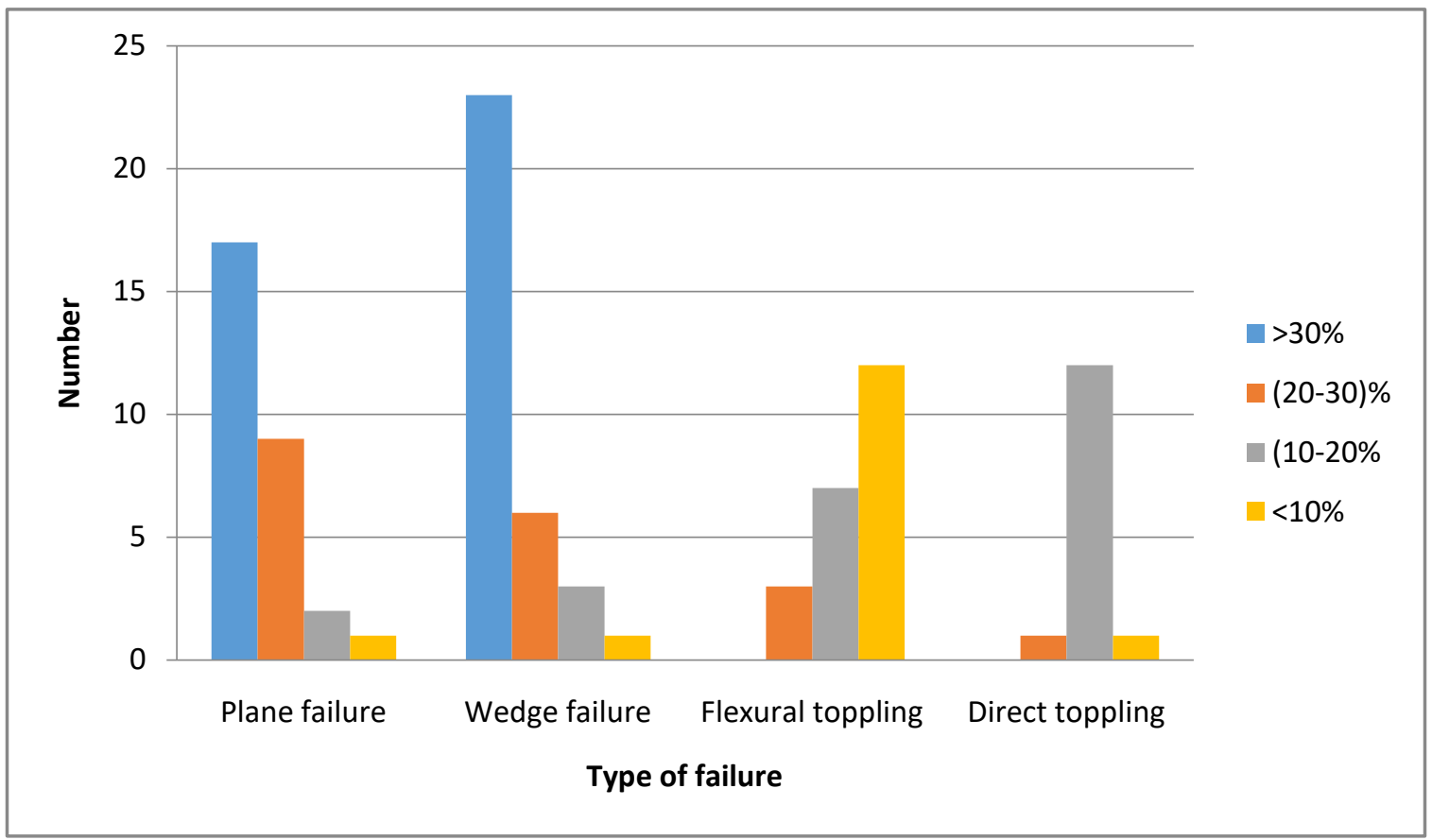

The result shows that toppling failure is rare in the study area (Fig. 7). Most of the failure are either plane or wedge failure. The plane failure is controlled by hill slope and rock orientation. The hill slope is steep and the dip direction of hill slope and bed rock is within $20^{\circ}$. So, the plane failure is probable in this area. The pole concentration of joints indicates that the area is potential for wedge and plane failure (Fig.8).

Result of this study is similar to the study carried by Tamrakar et. al.,(2013). They reported that wedge failure is major failure in the River bank. Slope failure in Nepal Himalaya varies in size. Several scientific studies reported the basic mechanism and processes of landslide in Nepal but most of these cases addressed only rainfall induced small scale and roadside slope collapses. Last three decade landslide record in Nepal reveals that road and human settlement slope are more vulnerable to failure than natural slope (Bhandary et. al., 2013). When discussing about large scale slope failure, we come with steep slope, as key feature to initiate it but according to Hasegawa et al. (2009) large scale one is the end of modification process in Himalaya region. 
Figure 8: Pole concentration of joints set

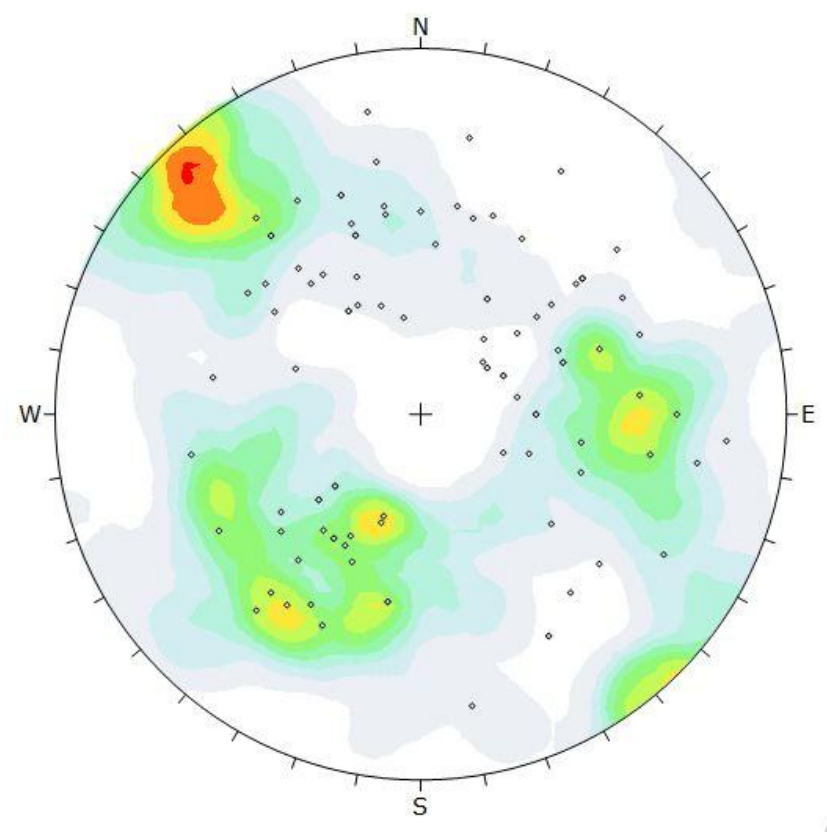

Figure $9 \& 10$ shows the typical plane and wedge failure of study area. In figure 9, the dip direction of hill and bed rock is in same direction. The rock type is sandstone. The hill slope is greater than $55^{\circ}$ but the dip amount of bedding is less than $45^{\circ}$. In lower hemispheric projection of figure 9, the joint has delighted the hill slope. Similarly, in figure 10, stereographic projection shows that the intersecting point between two joints lies between hill slope and friction angle.

Figure 9: Typical plain failure of the study area

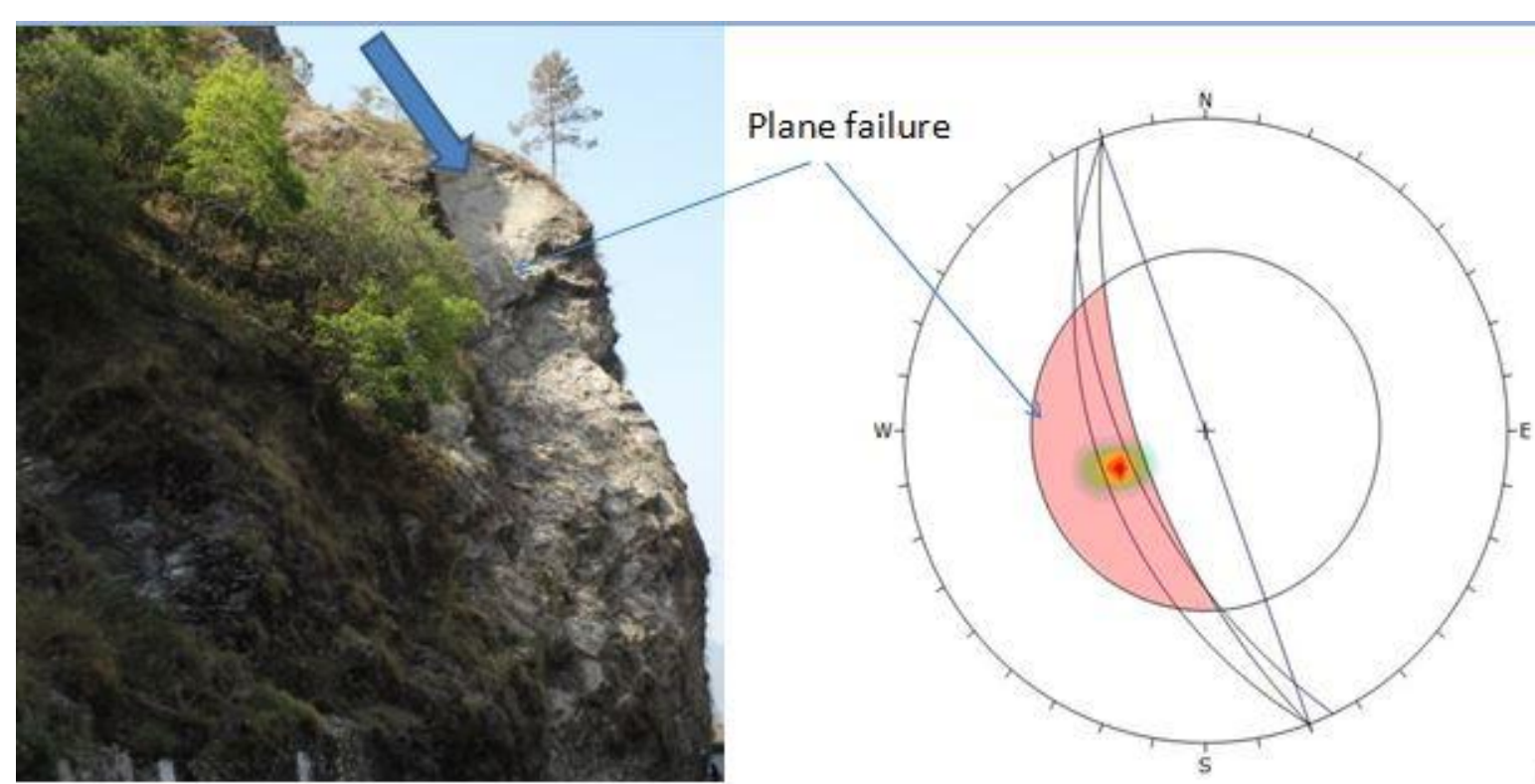


Figure 10: Typical wedge failure of the study area

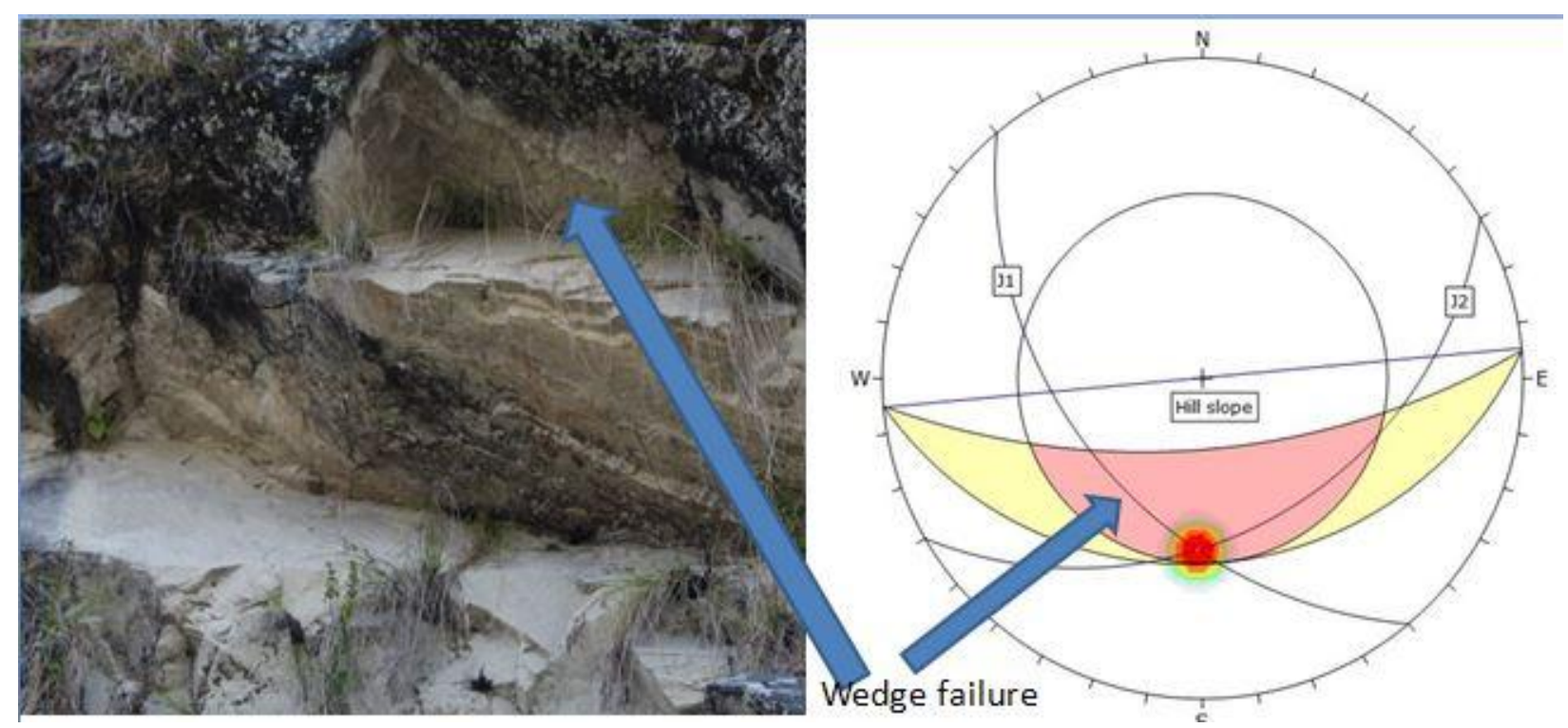

The large scale landslide mass usually has small-scale slope failures and incised drainages near the toe where road construction is practiced without adequately considering the consequences of possible reactivation of the relict landslide mass or the possibility of frequent slope collapses (Regmi et. al., 2014).

Our result is similar with some other researcher. Planar mode of failure is relatively simple failure and very common in stratified sedimentary and meta-sedimentary rock formations. The stability of slope having planar failure depends upon geometry, rock type, potential failure plane characteristics, groundwater condition and dynamic loading (Raghuvanshi, 2017). The orientation of joints and method of excavation of slopes also affect slope stability. Though result indicate the probability of all failure, most critical failure observed are two wedge and two plane with possibility greater than $50 \%$. This result also indicates that the large slope failure along roadside may be occurs due to haphazard blasting and excavation of slope during construction.

\section{Conclusion}

Kinematic analysis of joint set orientation and hill slope indicate that there is the probability of almost all types of failures but topple failures are found very less. Both natural and human induced slope failure causes the losses of numerous lives and damages the property each year catastrophically. Due to hill slope geometry and status of joints, the possibility of wedge failures is found higher in number. So, the road section of Bhasu bhir of Kailali, along the Bhimdatta Panta highway, is not safe for long-term where the probability of rock fall (wedge failure) is very high. 


\section{References}

Admassu, Y. (2012). User's Guide Dip Analyst 2.0 for Windows

Bhandary, N. P., Yatabe, R., Dahal, R. K., Hasegawa, S., \& Inagaki, H. (2013). Areal distribution of large-scale landslides along highway corridors in central Nepal. Georisk: Assessment and Management of Risk for Engineered Systems and Geohazards, 7(1), 120.

Chamlagain, D., \& Dangol, V. (2001). Slope Stability Analysis of the Mai Khola Rockslide, Ilam District, Eastern Nepal. Nepal Journal of Science and Technology, 3(1).

Goodman, R. E., 1989. Introduction to Rock Mechanics, John Wiley \& Sons, New York, USA, $562 \mathrm{pp}$.

Hasegawa, S., R.K. Dahal, M. Yamanaka, N.P. Bhandary, R. Yatabe, and H. Inagaki 2009. "Causes of LargeScale Landslides in the Lesser Himalaya of Central Nepal."' Environmental Geology 57 (6): 14231434.

Hughes, S. (2003). Slope Failure. Environmental Geology.

Hoek, E., \& Bray, J. D. (2014). Rock slope engineering. CRC Press.

Regmi, A. D., Yoshida, K., Nagata, H., \& Pradhan, B. (2014). Rock toppling assessment at Mugling-Narayanghat road section:'A case study from Mauri Khola landslide', Nepal. Catena, 114, 67-77.

Sanuja. (2016, april 23). Sanuja. Retrieved January 12, 2019, from Wikipedia: https://en.wikipedia.org/wiki/Discontinuity_(geotechnical_enginering).

Tamrakar, N. K., Singh, J. L., Bista, K. K., \& Maharjan, P. (2013). Toppling and wedge failures in Malekhu River area,Malekhu, Central Nepal Lesser Himalaya. Bulletin of the Department of Geology, 16, 21-28.

Umrao, R. K., Singh, R., Ahmad, M., \& Singh, T. N. (2011). Stability analysis of cut slopes using continuous slope mass rating and kinematic analysis in Rudraprayag district, Uttarakhand. Geomaterials, 1(03), 79.

Wyllie, D. C., \&Mah, C. (2014). Rock slope engineering. CRC Press.

Yoon, W. S., Jeong, U. J., \& Kim, J. H. (2002). Kinematic analysis for sliding failure of multifaced rock slopes. Engineering Geology, 67(1-2), 51-61. 